\title{
Uncanny Networks: Dialogues with the Virtual Intelligentsia
}

Geert Lovink, The MIT Press, USA, 2002, 392 pages, ISBN 0-262-12251-0 (hardback),

\author{
George Macgregor \\ Centre for Digital Library Research \\ University of Strathclyde
}

Recent developments in the so-called Information Society have facilitated a brand of cultural convergence that would hitherto have been imponderable. Of course, the greatest exponent of this new-found cultural convergence is the Internet; information, art, culture, science, and technology, all utilising the same vehicle for dissemination or expression. Constituting one piece of the Leonardo Series delivered by MIT press, Uncanny Networks continues a book series that attempts to holistically comprehend, analyse and provide intellectual discourse on this innovative convergence of disciplines. This concept of 'intellectual discourse' assumes an intriguing semblance when wielded by Lovink, who treats the reader to a collection of interviews with a diverse range of media and cultural theorists, philosophers, critics, information specialists and artists in an attempt to examine the numerous ideological, theoretical, social and political manifestations that have influenced the said cultural convergence. Thus Lovink provides the reader with perspectives on issues such as cultural imperialism, globalisation, the digital divide, and consumerism, to issues encompassing the supposed 'virtual class', the political economy of media, and the suspicion of post-modernity and liberal elitism. One might immediately think that such a mélange of conflicting perspectives would render a book wholly impalatable; ordinarily it might, but not in Uncanny Networks.

An outlandish self-interview by Lovink functions as an introductory road map of the book proper and provides the intellectual framework for the interviews that follow. Therein, interviewees challenge the utopian, euphoric, vibrant, and occasionally the cynical posturing associated with the Information Age, particularly in developing countries such as those in Eastern Europe and Asia which are now considered the new 'laboratories of experience', and in which we can yield a greater understanding of the Information Age. However, summarising a book that comprises thirty-five self-contained interviews, embodying numerous conclusions, is inappropriate for the purposes of this review. Rather, highlights include Herbert Schiller discussing 'Cultural Imperialism and Information Inequality', a discourse that leads him to consider modern society as culturally feeble, morally bankrupt, but simultaneously resembling a naïve or innocent child.

An accepted author manuscript of the following output: Macgregor, G. (2004), 'Uncanny Networks: Dialogues with the Virtual Intelligentsia by Geert Lovink', Library Review, Vol.53 No.6, pp.335-336. http://dx.doi.org/10.1108/00242530410544466 
In 'There is No Information, Only Transformation', Bruno Latour's response to the propaganda regularly espoused about globalisation and universality lead him to conclude that the reverse is occuring. Latour, bouncing ideas off Lovink, suggests that we have now entered an age of 'antiinformation', in which 'universality, fastness and immediacy' will stall in the face of local transformation, hierarchy, local values and taste. Says Latour, "the idea of information as immutability and mobility being non-contradictory, being able to flow everywhere, does not work at the level of science, nor at the level of computer or politics. We can make a safe bet that it will not happen". These are unquestionably controversial statements in an age of anti-antiinformation. Meanwhile, in 'Cyberselfishness Explained', Paulina Borsook explores cyber culture, particularly Silicon Valley and the Dot-com crash of 2000. Again with the help of Lovink, Borsook offers the opinion that the 'New Economy' never actually happened and was instead sheer financial speculation based on the intangible. She argues that such an arrangement was purely for short-term economic gain and was destined to fold in the long term. Needless to say, Borsook is extremely persuasive.

Based in Sydney, Geert Lovink is a media theorist, publisher and founder of the international mailing list 'Nettime', as well as an organiser of online forums, conferences, and interviewer for magazines such as 'Mediamatic' and 'Telepolis'. Such activity has clearly honed his methodology for conducting the quintessential social interface: penetrating, analytical and innovative. Moreover, he respects the true definition of 'interface', serving as a channel for the interviewee's ideas, but neither stepping inside nor outside of them. Whilst it helps if the reader has assimilated works by the likes of Heidegger or Nietzsche to interpret some of the views propagated by Lovink's interviews, Uncanny Networks is undoubtedly worth the slog. Not only is each interview a self-contained entity, but also appreciated as a collection, Uncanny Networks identifies key elements of the Information Society and projects the infinite possibilities, either for interdisciplinary analysis or for hypothesising about the future trajectory of society generally. More importantly, Uncanny Networks makes the reader think. Riveting stuff. 